\title{
Groundwater vulnerability assessment using an improved DRASTIC method in GIS
}

\begin{abstract}
Groundwater management can be effectively conducted by using groundwater contamination map assessment. In this study, a modified DRASTIC approach using geographic information system (GIS) was applied to evaluate groundwater vulnerability in Kerman plain (Iran). The Wilcoxon rank-sum nonparametric statistical test was applied to modify the rates of DRASTIC. In addition, the analytic hierarchy process (AHP) method was employed to evaluate the validity of the criteria and sub criteria of all the parameters of the DRASTIC model, which proposed as an alternative treatment of the imprecision demands. The GIS offers spatial analysis in which the multi index evaluation can be effectively conducted through the AHP. The non-point source pollution was effectively determined by the modified DRASTIC method compared with the traditional method. The regression coefficient revealed the relationship between the vulnerability index and the nitrate concentration. The best result was obtained by using AHP-AHP, followed by DRASTIC-AHP, modified DRASTIC-AHP, and AHP-DRASTIC models. In this study, the DRASTIC method failed to provide satisfactory result. Additionally, by using both the original DRASTIC and the modified DRASTIC methods in the study area, AHP-AHP performed highly in the Kerman plain, suggesting that the southern and south east parts of the area considerably calls for conservation against contamination.
\end{abstract}

Keyword: DRASTIC model; GIS; AHP; Hydrogeology; Kerman plain; Iran 